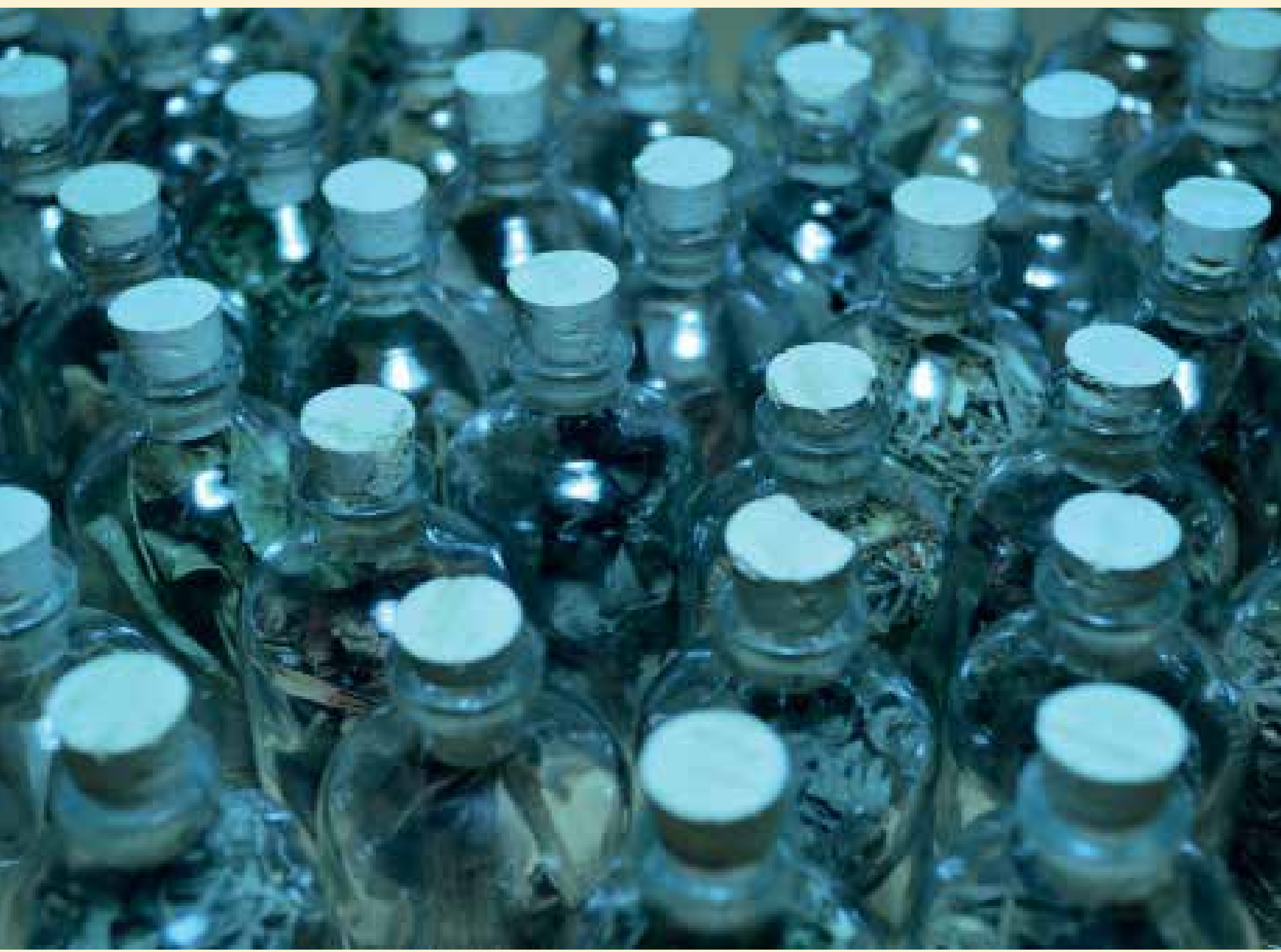

Sin título. Fotografía: Jesús Holmes Muñoz Gómez (2014). 


\section{El cuerpo perfumado. Los aromas de la intimidad femenina en Ifigenia (Teresa de la Parra, 1924) ${ }^{1}$}

The perfumed body. The aromas of female intimacy in Ifigenia (Teresa de la Parra, 1924) // O corpo perfumado. Os aromas da intimidade feminina em Ifigenia (Teresa de la Parra, 1924)

María Carmela Malaver Narváez ${ }^{2}$

Universidad Autónoma de Barcelona, España mcmalaver@hotmail.com

Revista Corpo-grafías: Estudios críticos de y desde los cuerpos / Volumen 7 - Número 7 / Enero - diciembre 2020 / ISSN impreso 2390-0288, ISSN digital 2590-9398 / Bogotá, D.C., Colombia / 93-105

Fecha de recepción: 15 de enero de 2019

Fecha de aceptación: 2 de mayo de 2019

DOI: h\#ps://doi.org/10.14483/25909398.15508

Cómo citar este artículo: Malaver Narváez, M C. (2020, enero-diciembre). El cuerpo perfumado. Los aromas de la intimidad femenina en Ifigenia (Teresa de la Parra, 1924). Revista Corpo-grafías: Estudios críticos de y desde los cuerpos, 7(7), pp. 93-105 / ISSN 2390-0288.

\footnotetext{
Articulo de Investigación: El presente artículo deriva de la investigación realizada por la autora para la tesis doctoral "Espejo, cuerpo e identidad en Ifigenia (1924)", para la obtención del título de Doctor en Humanidades / Filología Española por la Universidad Autónoma de Barcelona, 2016, bajo la orientación del Dr. Víctor Carreño y la Dra. Helena Usandizaga.

$2 \mathrm{PhD}$ en Humanidades / Filología Española por la Universidad Autónoma de Barcelona, 2016. Pertenece a la Línea de investigación: Identidad femenina, cuerpo, espejo, olfacción, moda, perfume, belleza. Actualmente presta servicios profesionales de asesoría académica, corrección de textos, y docencia. Ha publicado diferentes ensayos y artículos en: Situarte, Escribir con el cuerpo, Prácticas corporales en la búsqueda de la belleza, entre otros.
} 


\section{Resumen}

El perfume y los olores tienen una especial relevancia en la novela Ifigenia (1924) de Teresa de la Parra. Este sutil elemento revela secretos de la sociedad desde el punto de vista sociológico, cultural, antropológico y comunica un mensaje. Se hará un breve recorrido por la historia del perfume. Desde esa base se hará una aproximación a la olfacción en la novela Ifigenia, donde el perfume y los olores aportan matices a la identidad de los personajes principales, develando secretos del alma de la casa crioIla. Se utilizará la metodología interpretativa para analizar la relevancia del perfume en la obra y demostrar cómo la autora se vale de la olfacción para la construcción del sentido de la novela, descifrando un código para transmitir un mensaje. Nos serviremos de algunos teóricos de la olfacción, el perfume, el cuerpo y la identidad, entre ellos: Vroon, Corbin, Freud, Squicciarino, Foucault, Sáez, Mattalía, Torras.

\section{Palabras clave}

Cuerpo; identidad; literatura femenina; olfacción; perfume

\section{Abstract}

The perfume and the smells have a special relevance in the novel Ifigenia (1924) by Teresa de la Parra. This subtle element reveals the society's secrets from the sociological, cultural, anthropological point of view and communicates a message. There will be a brief tour about the history of perfume. From that base, an approach to olfaction will be made in the novel Ifigenia, where the perfume and smells add nuances to the identity of the main characters, uncovering the soul's secrets of the Creole's house. The interpretive methodology will be used to analyze the relevance of perfume in the work and to demonstrate how the author uses olfaction to construct the meaning of the novel, deciphering a code to transmit a message. We will use some theorists of olfaction, perfume, body and identity, among them: Vroon, Corbin, Freud, Squicciarino, Foucault, Sáez, Mattalía, Torras.

\section{Keywords}

Body; feminine literature; identity; olfaction; perfume

\section{Resumo}

O perfume e os cheiros têm uma relevância especial na novela Ifigenia (1924) de Teresa de la Parra. Este sutil elemento revela segredos da sociedad desde o ponto de vista sociológico, cultural, antropológico e comunica uma mensagem. Se fará um breve recorrido pela história do perfume. Desde esta base, se fará una aproximação olfativa da novela Ifigenia, onde o perfume e os cheiros aportam matizes à identidade dos personagens principais, revelando segredos da alma da casa criola. Se utilizará a metodología interpretativa para analisar a relevância do perfume na obra e demostrar como a autora se vale do olfato para a construção do sentido da novela, decifrando um código para transmitir uma mensagem. Nos serviremos de alguns teóricos do olfato, do perfume, do corpo e da identidade, entre eles: Vroon, Corbin, Freud, Squicciarino, Foucault, Sáez, Mattalía, Torras.

\section{Palavras-chave}

Corpo; identidade; literatura femenina; olfato; perfume

\section{A modo de preámbulo: breve historia del perfume. La olfacción y la memoria invo- luntaria}

Para introducirnos en el tema del perfume, haremos un breve recorrido por algunos parajes de la historia de la perfumería. El olfato en occidente no ha sido un sentido tan valorado como la vista y el oído. El estatus del olfato, según nos comenta Vroon, ha sido juzgado en occidente de diversas maneras. Algunos filósofos asumieron su postura respecto a la olfacción, entre ellos Platón (citado por Vroon, 1999) quien sentenció los perfumes como se ilustra en esta cita: 
Platón lanzó un anatema contra los perfumes, pues, a su juicio, las esencias provocaban el afeminamiento e inducían al placer carnal. El uso de fragancias era algo propio de las prostitutas. Las personas virtuosas debían preocuparse principalmente por el bien del alma, mediante la música y la práctica de las matemáticas (...) Además al hallarse situada la nariz cerca del cerebro, se suponía directamente relacionada con sentimientos y deseos que convenía desterrar. (pp. 14-15)

En contraposición tenemos la visión de Sócrates (parafraseado por Vroon, 1999) quien: "fue algo menos dogmático respecto a este asunto. En su opinión, los olores eran un reflejo de la clase social a la que uno pertenece, de modo que le confería al olor un cierto valor informativo" (p.15).

Acerca de la gran valoración que se le daba a la vista y al oído comenta: "En las relaciones sociales, la vista y el oído se concebían como sentidos 'nobles', pues, según Platón, éstos ponen al hombre en contacto con el mundo de la perfección" (Vroon, 1999, p. 15). Los otros filósofos continuaron dando poca valorización al olfato, salvo algunas excepciones:

Los filósofos posteriores tampoco tocaron apenas el tema del olfato $y$, cuando lo hicieron (por ejemplo, Immanuel Kant a finales del siglo XVIII), fue generalmente para desacreditarlo. Todo esto explica en parte por qué apenas se investigó el funcionamiento del olfato y, en cambio, se le prestara mucha más atención a la vista. (Vroon, 1999, p. 15)

Freud también se pronunció acerca de la función del olfato, el cual, como se ha venido explicando, por estar asociado a lo instintivo y lo sexual continuaba siendo bastante desvalorizado. A ese respecto dilucida la razón por la cual se desestima el olfato y se valida más lo visual:

Aunque la periodicidad del proceso sexual ha persistido, su influencia sobre la excitación sexual psíquica se transformó más bien en lo contrario. Esta reversión depende ante todo del atenuamiento que sufrieron las excitaciones olfatorias, mediante las cuales la menstruación influía sobre el psiquismo masculino. La función de las sensaciones olfatorias fue asumida por las visuales, que podían ejercer efecto permanente, al contrario de las olfatorias, cuya influencia es intermitente (Freud, 2002, p. 251).

Según Freud, la atenuación de las sensaciones olfatorias viene a ser una consecuencia de distanciarse el hombre de la tierra adoptando la marcha bípeda. Por otro lado "Rousseau y Goethe reconocieron, (...), la enorme importancia de la intuición y el valor de las emociones y hasta llegaron a ensalzar el sentido del olfato" (Vroon, 1999, p. 22). Una conocida frase de Rousseau es "el olfato es el sentido del recuerdo y el deseo", lo cual denota la valorización que le daba a este sentido. Otros intelectuales se alían también al poder de la fragancia como correspondencia de lo sublime y lo celestial. Suele asociarse a George Sand la cita: "El recuerdo es el perfume del alma"; es muy sabido el gusto de Sand por los olores.

Según Vroon: "El impulso más fuerte que acrecentó el interés por el olfato, especialmente en el siglo XVIII y a principios del XIX, lo dio la medicina" (1999, p. 16).

Vroon (1999) y Corbin (1987) nos explican que la terapia de los olores se unió a la medicina para contrarrestar la podredumbre, los hedores e infecciones que flotaban en el "mal aire". Para ello empleó los olores como terapia (aromaterapia, osmoterapia, baños de hierbas medicinales) y en este campo aparecen los "higienistas" y consejos de salud pública, los cuales intentaban combatir los hedores de las ciudades, hospitales, cárceles y viviendas. Un paso importante es que se construyen sistemas de alcantarillados cerrados.

A esto se une la costumbre del baño según el cual "el cuerpo podía liberarse, gracias a una piel limpia, de los efluvios malignos, y esta idea hizo que se dictaran gran cantidad de instrucciones para el baño" (Vroon, 1999, p. 21). 
A mitad del siglo XVIII, el olfato pasa a formar parte de las nuevas representaciones de la elegancia. El perfume refuerza el estatus, la clase social y envuelve en una esfera de ensueño a quien lo usa.

Los perfumes no solo formarán parte de la atención y cuidado del cuerpo, sino que también se extenderán e incorporarán a la habitación burguesa. Este nuevo ambiente autoriza una sabia puesta en escena de la mujer, la cual forma parte de esta nueva manera de concebir la esfera íntima, donde se revalorizan los olores. Es interesante resaltar que de todo lo que se ha venido explicando lo más notable de esa historia de la perfumería -lo que Corbin ha denominado la "Revolución perceptiva"es la revalorización de los olores, un avance en el tema de la olfacción que queda registrado: "A partir de mediados del siglo XVIII, se bosqueja un movimiento estético que tiende a hacer del olfato el sentido generador de los grandes movimientos del alma" (Corbin, 1987, p. 98).

La falta de prestigio de los olores, tanto para los filósofos como para el resto, según explica Vroon, hace que no abunden los olores en la literatura narrativa. Rara vez el olfato desempeña un papel protagonista en la literatura reciente. A ese respecto agrega:

Lo que sí suele mencionarse a menudo es la capacidad de los olores de activar la memoria. En la célebre novela de Proust, el olor de una petite madeleine mojada en el té despierta una sensación de felicidad (...) Gracias a los olores, Proust recordará toda suerte de vivencias, algunas de ellas muy lejanas. (1999, p. 160)

Esa temática de la memoria involuntaria de Proust activada a través del olor en este caso está muy relacionada con la memoria involuntaria en la obra de Teresa de la Parra, quien también activa el recuerdo a través de los olores, entre otros dispositivos.

En la novela Ifigenia, como veremos más adelante, los olores están muy presentes. Esa manera detallada que poseía De la Parra de hacer remembranzas del pasado a través de los olores ha sido asociada al estilo de Proust por el crítico Marco Antonio Martínez, quien pone de manifiesto la capacidad de la autora de atrapar el recuerdo como forma de su tiempo vital y convertirlo en una realidad novelesca. (Martínez considera que la novela Ifigenia tiene una influencia proustiana).

Los olores tienen una especial relevancia en la novela Ifigenia e influyen en los estados anímicos y emociones de la protagonista. Según Vroon (1999) "Los olores (provengan o no de nosotros mismos) nos comunican algo acerca del entorno en que nos hallamos" (p. 163). De la Parra, se sirve de los mensajes contenidos en el perfume y los olores como recurso para consolidar la esencia de algunos personajes y espacios.

A través de este elemento también se devela el alma de la casa criolla. El tema de los olores es una constante en la novela y nos conecta a veces con la memoria involuntaria. María Eugenia es muy sensorial, especialmente olfativa y pone especial atención a las fragancias que la rodean, siendo los olores y el perfume uno de los pilares fundamentales en la construcción del sentido de la novela.

La heroína es muy sensible a los olores y describe el entorno doméstico cargado de diferentes fragancias que influyen en sus estados de ánimo. Su identidad estará sellada con el perfume que usa, Nirvana de Bichara, el cual apoyará el proceso de construirse a placer e irradiar seguridad, ya que cuando usa esta fragancia, según describe, se eleva su espíritu. Por otro lado se pudo demostrar que el perfume Origan de Coty que usa el personaje César Leal (novio impuesto por la familia) actúa de forma determinante produciendo un choque en María Eugenia (personaje principal de Ifigenia); la fuerza de esta fragancia invade y domina, se pudo mostrar que posiblemente algunos de los ingredientes de ese perfume, o lo que se conoce como la "frase olfativa", pueden alterar la 
percepción y las emociones de la heroína, e influir en las decisiones que toma desatando la tragedia.

El perfume es una suerte de aura que surca el camino, se instala temporalmente en nuestro paso y crea una atmósfera propia; es una conquista del espacio individual, una manera de crear fronteras; es una esfera que recubre y crea límites...también permite al cuerpo transmitir un mensaje silencioso y certero que genera un efecto en el otro. A ese respecto Squicciarino (1990) expresa: "En el ámbito de la comunicación, el perfume, ampliando el propio yo corporal, potencia el cuerpo como productor de mensajes y al mismo tiempo como extensión de las capacidades de reacción sensorial por parte del virtual destinatario del mensaje" (p. 64). También a este elemento se le otorga un poder mágico porque puede inducir a otros estados de consciencia y éxtasis como se demuestra en esta cita:

A esa sustancia etérea siempre se le ha atribuido un poder purificador con respecto a la materialidad y a lo instintivo, así como la cualidad de refinar y elevar el espíritu. Como afirma Frazer, el uso del perfume en algunos pueblos primitivos tenía la finalidad de suscitar un estado de éxtasis y de inspiración, así como la de ahuyentar los poderes maléficos, dar caza a los espíritus malignos y exorcizar a las brujas. (Squicciarino, 1990, p.64)

En la novela podemos apreciar cómo el perfume activa un estado de éxtasis en la heroína cuando aplica su perfume Nirvana de Bichara, lo cual se ampliará más adelante.

\section{Los aromas de la intimidad femenina en Ifigenia}

La protagonista de Ifigenia (María Eugenia Alonso) es muy sensitiva y perceptiva; ella nombra y clasifica los aromas de su entorno: el olor de los naranjos del patio, el perfume de los azahares, el Ellimans Embrocation (que usa la Abuelita para los dolores), el perfume a limpio de Gabriel, el olor a tierra húmeda, a jazmines y a cera de las velas de la casa, el perfume de Mercedes, el olor a L'Origan de Coty y a tabaco de su pretendiente (Leal) y todos los olores que emanan los espacios, las personas y que retratan a la casa criolla de fin de siglo. Esos olores pueden transportarla, trastocarla o pueden hacerla soñar, confundirla, aturdirla, o también aburrirla, tal y como expresa a su amiga Cristina en el fragmento epistolar, donde afirma que se aburre aspirando estos olores y demostrando así su sensibilidad olfativa, lo cual queda registrado en esta cita:

(...) no podrás figurarte nunca lo que yo me fastidio desde hace un mes, encerrada dentro de esta casa de Abuelita que huele a jazmín, a tierra húmeda, a velas de cera, y a fricciones de Elliman's Embrocation (...). Pero iay! Lo que yo me fastidio aspirando estos olores sueltos o combinados, mientras miro coser o escucho conversar a Abuelita y tía Clara es una cosa inexplicable. (De la Parra, 1996, l, p.30)

La protagonista de Ifigenia (María Eugenia Alonso) es muy sensorial, especialmente olfativa. Como se puede apreciar en la narración, la heroína toma consciencia de los olores que la rodean. Existe una conexión entre el personaje, la identidad que crea a través del perfume y el efecto de los olores en su comportamiento. Los dos perfumes citados en la novela, L'Origan de Coty y Nirvana de Bichara, reflejan la identidad de los personajes que lo utilizan y ambos producen un efecto en las emociones de la protagonista.

Teresa de la Parra se vale del perfume y los olores para realzar la identidad de los personajes y los espacios en la novela objeto de estudio. Con el uso de los olores la autora logra ese efecto doméstico tan criollo de la casa colonial caraqueña de fin de siglo. Al esparcir los aromas característicos, otorga realismo y vida a la historia relatada, tanto en el fragmento epistolar como en el diario ficticio. 
El ritual del arreglo que realiza la heroína incluye perfumarse como parte de la construcción de la imagen de belleza y elegancia. El perfume se convierte en sello de identidad. Para afianzar este juego de la personalidad sometida a un devenir, que se expresa a través del perfume en la obra, nos apoyaremos en el concepto de identidad de Mattalía:

Toda pregunta sobre la identidad es una pregunta sobre el origen y toda respuesta -individual o colectivaimplica la fabulación de un comienzo, de un principio fundacional que se mitifica y transforma en relato. Cada época, cada cultura, cada sujeto, reconstruyen, matizan o recrean ese relato otorgándole un valor que dirige el sentido hacia el futuro y colorea sus propios objetivos y realizaciones. (Mattalía, 1995, p.91)

En la novela esa pregunta sobre la identidad puede ser respondida a través de elementos muy sutiles, pero reveladores de la cultura y la historia, tanto individual como colectiva, que se refleja en el perfume.

\section{El cuerpo perfumado. El Nirvana de Bicha- ra como sello identitario}

La construcción de la belleza y la identidad de la heroína en la novela, es potenciada con el uso del perfume; en su acicalamiento diario la muchacha incluye el uso del Nirvana de Bichara.

Como ya se ha comentado, a partir de la mitad del siglo XVIII el olfato empezó a formar parte de las nuevas representaciones de la elegancia. Es lo que Corbin denominó la "Revolución perceptiva". La novela Ifigenia se desarrolla en el siglo XX, pero tanto la protagonista como su autora vienen del siglo XIX, con lo cual se encuentran inmersas en ese despliegue de los olores que proviene de la "Revolución perceptiva" donde se otorga un alto valor a los sutiles mensajes corporales. Perfumarse se convierte en una práctica de sanidad, coquetería, insinuación sutil, elegancia, narcisismo, expansión del yo corporal; siendo una manera de invadir al otro a través de los sentidos, una sutil forma de entrar en el otro a través del aire que respira. El perfume se convierte en estrategia de seducción, Corbin (1987) lo destaca en la siguiente cita:

La invitación del aroma, más delicada y menos evidente y vulgar, puede turbar más que las fascinaciones de la desnudez; corresponde más a las ambigüedades de la intención seductora. Presenta, además, la ventaja de preservar las apariencias de inocencia. Los mensajes amorosos que se desprenden del cuerpo perfumado, no podrían hacer a un lado el pudor de las involuntarias redondeces escondidas, pero reveladas y quizás acentuadas, por la tela de la blusa. (p. 205)

La mujer podrá insinuarse a través de su perfume en total silencio sin ser juzgada. Llama la atención que aunque el perfume sea una forma de insinuación certera e infalible no sea tomada como impropia, siendo un arma que la mujer podrá usar para transmitir su mensaje sin que nadie pueda callarlo ni juzgarlo.

Aunque el recato y el decoro de la mujer sea un tema recurrente en la novela estará permitido expresarse e insinuarse a través de los aromas, por eso podría considerarse al perfume un recurso, treta o estrategia de seducción. Corbin (1987) confirma la importancia de esa estrategia donde la insinuación sutil busca despertar el deseo con matices de inocencia en la siguiente cita:

La atmósfera de la mujer se convierte en el elemento turbio de su sex-appeal. La exaltación de la virginidad de la joven, las nuevas representaciones de la esposa, de su papel y de sus virtudes continúan, sin embargo, prohibiendo la solicitación indiscreta. Despertar el deseo sin traicionar al pudor, tal es el papel que se otorga al sentido de oler en el refinamiento del juego amoroso que manifiesta la nueva alianza de la mujer con la flor. (1987, p.194)

Es importante destacar que los perfumes de la intimidad rescatan la conexión con la naturaleza y restauran la alianza entre la mujer y la flor, una idílica representación 


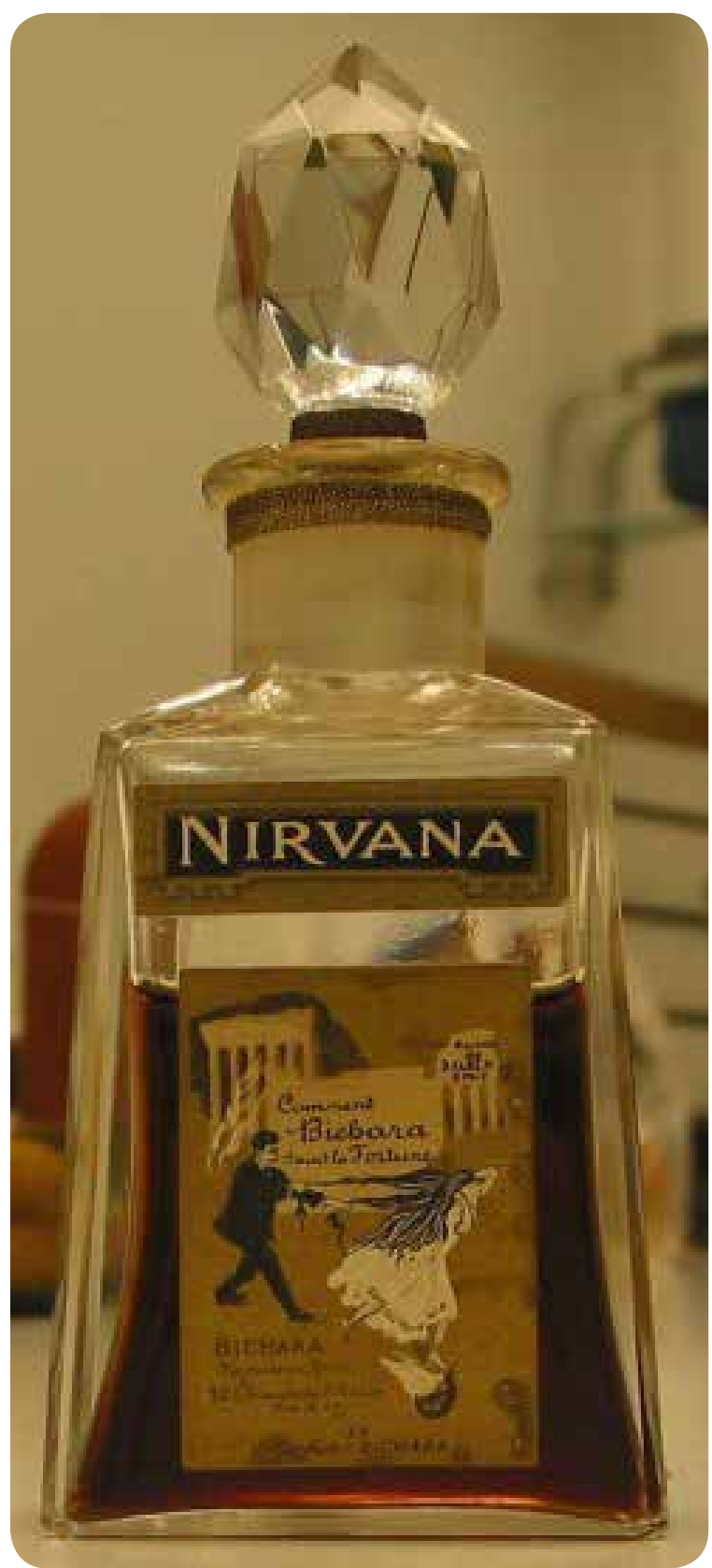

Imagen 1. Frasco del perfume Nirvana de Bichara. Fotografía: Archivo de The Museum of Fine Arts of Houston. Fuente: https://www. mfah.org/art/detail/60461? returnUrl=\%2Fart\%2Fsearch\%3Fartist\%3Dfor\%2BParfums\%2BBichara de la pureza, lo virginal, la doncellez y la ensoñación femenina. Esa alianza logra una idealización casi mística de la mujer, la cual ha estado muy presente en el arte.

El perfume es una evidencia de lo que somos secretamente, respalda nuestra proyección, ya que la escogencia de una fragancia es muy personal. Si bien a veces hay cierta influencia de las modas olfativas, las esencias generalmente serán escogidas con base en el agrado que producen. Esa selección irá condicionada por la relación cercana con determinadas hierbas, plantas, flores, materiales, raíces, resinas, entre otras, y la química de cada cuerpo hará el resto.

El mensaje que se despliega a través de la fragancia es una muda expresión a veces más sincera y precisa que las palabras, porque hay fragancias que gritan lo que la boca calla y no hay manera de escapar a ese mensaje.

En la novela Ifigenia podemos apreciar varios elementos derivados de la Revolución perceptiva, donde la habitación burguesa, el cuerpo y los espacios son potenciados con aromas: el pañuelo perfumado de Leal, el trousseau de la protagonista perfumado con "un olor a París que es una gloria", la fragante cajita que contiene las esmeraldas de la abuela (con olor a cedro y a vetiver). Estos detalles ponen de manifiesto que también en la burguesía de la Caracas de fin de siglo XIX e inicios del XX se incorporaron los olores en el espacio privado.

Del perfume Nirvana de Bichara se conservan pocos registros porque no fue considerado un clásico, sin embargo nos aproximaremos a su esencia a través del poco registro que hay de él, respaldado por las referencias que se hacen en la novela estudiada y algunas alusiones adicionales como la publicidad del mismo. Davis (2006) hace mención a la esencia de ese perfume en columnas de revistas de moda, en ese particular expresa: 
Although the Ballets Russes is never mentioned explicitly in this column, the troupe is invoked via a large advertisement that appears just beneath the text, promoting the Bichara perfumes "Sakountala" and "Nirvana", with capture "the voluptuous feeling of the Ballets Rousses" and conjure "the decorative seductions of Schehérezade". As this pairing of commentary and advertisement suggest the popularity, glamour, and high society cache of the Russian dancers was crucial to the solidification of the link between fashion and music, and helped to legitimize the discussion of fashion in the serious music press (p. 21).

Como se puede ver el alma del perfume Nirvana es captada de esa naturaleza etérea de los Ballets rusos y de la seducción de "Schehérezade". De esa esencia se nutre también la moda de ese momento, cuyo estilo está asociado a la indumentaria de la autora y su personaje. El carácter de ese perfume combina con la moda de la época publicada en La Gazette du bon ton creada por Paul Poiret, diseñador de modas, creador y editor de la revista. Weill nos refiere ese momento histórico (asociado a la esencia de la fragancia Nirvana) cuando comenta:

El Art Nouveau se ha agotado (...) El relevo ya está allí, acechando: la fanfarria multicolor de los Ballets rusos lo hará salir a luz pública. Su jefe indiscutido, su padrino es Paul Poiret, 'el pachá de París', gran modisto interesado en todo (...). (2000, p.5)

El perfume Nirvana de Bichara se sustenta en ese nuevo espíritu. Las revistas, la moda, el arte y todo se impregna de la influencia de los Ballets rusos, lo cual puede captarse a través de la publicidad de la época, donde los cuerpos despliegan ese etéreo esplendor. Tanto la autora de Ifigenia como su protagonista están impregnadas de esa esencia.

En el pasaje de la novela donde la protagonista (María Eugenia) recibe flores de su pretendiente se destaca el efecto de los olores en su espíritu. Ella llena su habitación con esas flores y luego se perfuma, como puede observarse en esta cita: “(...) mientras que mi atención admiraba el matiz de las flores, aspiraba voluptuosamente aquel tenue y complicado perfume hecho con rosas, orquídeas y Nirvana de Bichara,..." (De la Parra, 1996, II, p.83), a eso se agrega: "Y contemplando mi obra, y aspirando el aire con las narices esponjadas me quedé en éxtasis mucho rato (...)" (De la Parra, 1996, II, p.82).

En esta escena se puede apreciar que el sujeto femenino se regocija en el acto de oler, creando un ambiente para la ensoñación en su habitación con las flores y el perfume. Vemos claramente esa simbiosis de María Eugenia con la naturaleza y las flores; fabrica un escenario, una atmósfera de ensueño, valiéndose de las flores que le ha enviado el pretendiente, llenando con ellas toda la habitación.

Con esto el espacio íntimo se impregna de la fragancia que emanan las flores, la cual se junta con la de ella: Nirvana de Bichara. En este caso el perfume otorga un valor más especial a la atmósfera y la intimidad de lo femenino. Conviene resaltar que ella misma afirma estar en éxtasis, y en ese estado afirma:

¡Ah! mi cuarto ya no era mi cuarto, sino una estancia novelesca y encantadora en donde flotaba el más sutil y delicioso perfume. Me acordé del boudoir oriental de Mercedes Galindo, siempre lleno de flores, que tanto me había cautivado en otros tiempos y por imitarla a ella, me puse mi déshabillé de encaje crema; arreglé frente al espejo los áureos tufos de mi pelo; me perfumé el cuello con Nirvana de Bichara, ... (De la Parra, 1996, II, p.82-83)

El perfume Nirvana es su huella o sello identitario, expresión auténtica de las sutilezas de su alma. También actúa como dispositivo que afecta positivamente las emociones, al punto de ser otro elemento liberador.

El perfume y la escritura pueden considerarse armas o tretas para alcanzar la liberación en el espacio personal, 
privado y cotidiano del encierro. Perfumarse la trastoca, la eleva, la evade de esa realidad donde se siente prisionera. La fragancia hace que el alma se expanda, se eleve y se libere lejos de su realidad. Esto la empodera, y aunque se encuentre en la prisión de su habitación puede escribir, leer, volar lejos, soñar y reinventarse. Por eso ella se perfuma en la intimidad para sí misma, creando un personaje y una identidad; en este caso el perfume le permite liberarse, crear y disfrutar esa identidad.

María Eugenia legitima un espacio íntimo de ensueño apoyándose en los olores. El efecto de su perfume y el de la fragancia de las flores la vuelven etérea, embriagada de sí misma y puede representarse a su antojo. Los aromas le permiten jugar ese papel, crear un performance y huir de su realidad inmediata.

Toda esa magia de la atmósfera que la rodea la inspira para crear un personaje, una identidad similar a las chicas de las novelas que suele leer. También alimenta su hedonismo, su vanidad, cuidando cada detalle para encarnar su personaje, apoyada en la indumentaria, embriagada de olores y saboreando bombones. La esfera de ensueño placentero y sensual alimenta el tacto, el olfato, la vista, el gusto, una fiesta de los sentidos que protagoniza el cuerpo de la heroína, lo cual queda registrado en esta cita:

(...) envuelta en el deshabillé de encaje crema, con la novela inglesa entre las manos, perfumado el cuello y perfumados los brazos con Nirvana de Bichara, a más de contemplar los matices de las flores y a más de aspirar su delicioso aroma, pude también tomar de tiempo en tiempo de mi bombonera de cristal un perfumado y sabrosísimo dulce marca Boissier,... (De la Parra, 1996, II, p.97)

Esa sinestesia de imágenes sensoriales nos conecta con la estética simbolista. Balakian nos aproxima a esto a través de los últimos versos del poema de Baudelaire Correspondances del cual comenta:

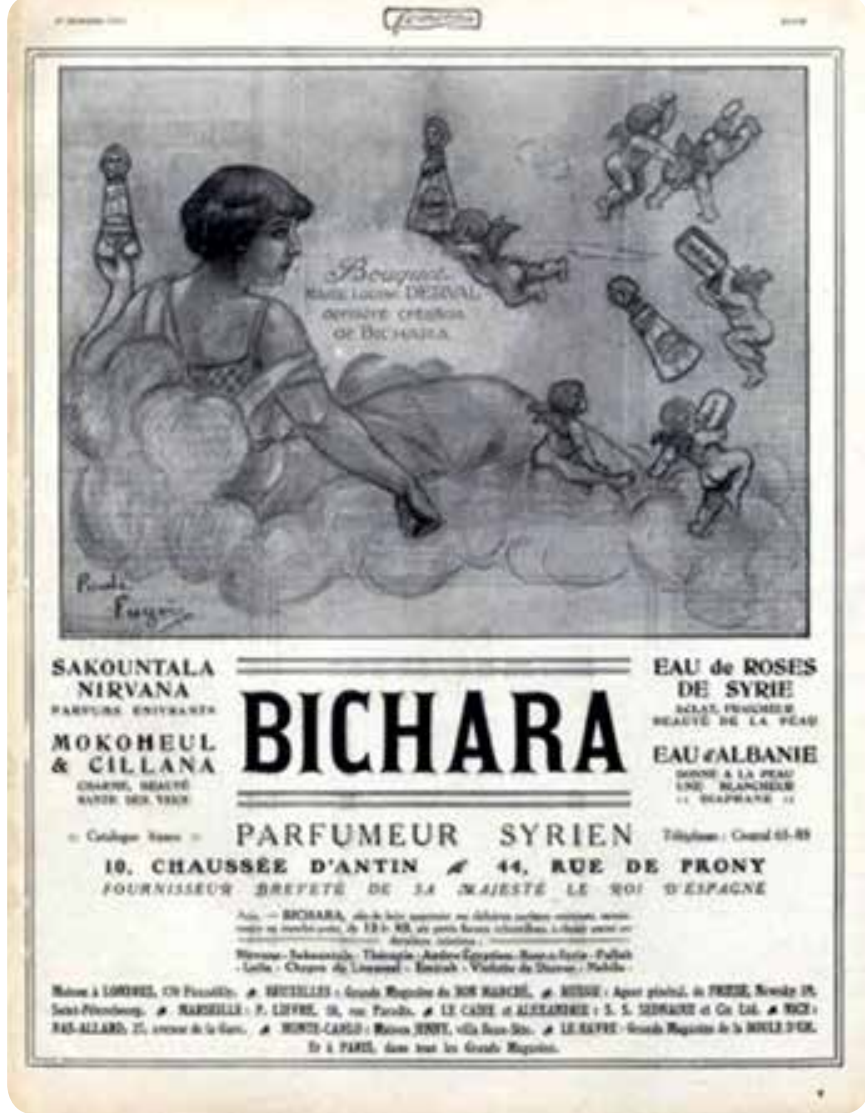

Imagen 2. Publicidad de los perfumes de Nirvana. Fuente: https:// www.parfumo.net/Perfumes/Bichara/Nirvana (revisada 1 de octubre de 2019).

En el último verso, Baudelaire, revela que el secreto para alcanzar la sinestesia no reside en la visión interior y su contacto con lo divino, sino más bien en la conexión con la mente (I'sprit) con los sentidos (les senses) mediante estímulos naturales como el incienso o el ámbar. La sinestesia es estrictamente terrenal, descriptiva del tipo de asociación en cadena que los estímulos sensuales pueden producir en la mente humana, y de las que después Proust extraerá su concepto de la memoria involuntaria (Balakian, 1969, p.52). 
Tal y como expresa Balakian en la cita anterior la sinestesia es alcanzada en la conexión con la mente y los sentidos mediante estímulos naturales que, en el caso de Baudelaire, es logrado a través del olor del incienso y el ámbar. La protagonista de Ifigenia se vale de las fragancias del perfume y las flores para crear una atmósfera sensual en su habitación a través de esas experiencias sensoriales, una relación íntima con sus sentidos.

La sinestesia producida por sus propias percepciones sensoriales la inspiran. La experiencia corporal hedonista desencadenada por el olfato, el tacto, el gusto, la vista y que es mayormente potenciada por el perfume le permite viajar y expandirse más allá de su cautiverio; podría decirse que el perfume es un dispositivo que activa el ensueño en la muchacha, como expresa en esta cita: "Suavemente embriagada por tan sutil perfume, durante un largo rato, me di a volar sobre sus alas por los deliciosos meandros y vericuetos de mil delicadísimos ensueños" (De la Parra, 1996, II, p.83).

Con la experiencia del cuerpo perfumado nuestra protagonista logra una conexión entre corazón y espíritu, ya que el perfume permite rescatar una comunión esencial y primigenia entre el hombre y la naturaleza. Este elemento posee entonces una connotación profunda: conecta al individuo consigo mismo rescatando su unidad, despertando el instinto. Robert Mauzi analiza este intercambio entre la naturaleza y el hombre, lo cual queda registrado en esta cita:

La unidad entre la naturaleza y el hombre da a éste la ilusión de una unidad interior en él mismo. Esta sensación le restaura el hilo que entre el corazón y el espíritu se había roto. Un perfume simple se convierte en una toma de consciencia de sí. Ésta tiene por efecto asociar su yo a la naturaleza, hasta ese instante extraña. (Citado en Corbin, 1987, p.100)

Sin embargo, esa toma de consciencia en María Eugenia se hace desde un cuerpo fronterizo, ya que según la teo- ría de Torras (2007), el cuerpo se relaciona bidireccionalmente con el entorno sociocultural. Su perfume, aunque es una elección personal e íntima, va influido también por la esencia del medio que le rodea y que retrata una época y un modelo de mujer.

Cuando María Eugenia se prepara para conocer a su pretendiente se acicala con mucho cuidado y cierra este ritual del arreglo con un aura de ensueño de Nirvana de Bichara. Así la muchacha se deja cautivar y elevar por su propio perfume, el cual junto con la indumentaria elegida para la ocasión la hace sentir empoderada, tal como se demuestra en la siguiente cita:

(..). Con un andar ágil, lleno de elasticidad y de elegancia, dejando tras mis pasos una deliciosa estela de Nirvana de Bichara y ostentando aquella actitud de importancia y displicencia que debe adoptar toda mujer distinguida cuando piensa desdeñar a un pretendiente, me encaminé al salón. (De la Parra, 1996, II, p.87)

La fragancia realza su apariencia exterior, la hace sentir grande, importante, superior, ubicada en una esfera muy alta, aunque eso es solo una parte del efecto, ya que ese mismo perfume que la envuelve fomenta el ensueño, la vuelve inmaterial, sublime, elevada, etérea, sutil, segura de que el poder de su belleza la mantendrá en ese nivel de altura y eso hace que despierte su ego queriendo desdeñar al pretendiente. En este caso podemos decir que el perfume expande el yo corporal, ya que rodea el cuerpo físico y crea como un halo de luz expandido, un espacio más allá del mismo cuerpo y que incluso puede permanecer más tiempo que la presencia física, es lo que los perfumistas Ilaman "estela", ${ }^{3}$ el olor que permanece luego del paso de una persona perfumada.

El empoderamiento, la magia y esa aura de ensueño que rodea a María Eugenia, derivada de su perfume, se des-

3 Vale la pena destacar que la autora, Teresa de la Parra, usa el término "estela" como se pudo ver en la cita anterior, lo cual denota un conocimiento de términos de perfumería. 
vanece cuando inhala el perfume del pretendiente: L’Origan de Coty. El impacto que le produce la hace aterrizar, su ánimo decae, pierde toda su seguridad. Como ya se ha dicho, Nirvana de Bichara es parte de su identidad y en ella busca su reflejo. Su estela perfumada se convierte en parte de ella, de lo que emana, se expande más allá de su cuerpo y le sirve para representar a la princesa cautiva convertida en objeto del deseo -puesto que ella quiere ser admirada y despertar deseo en el otro sin ser tocada-. Su coquetería y vanidad necesitan despertar el deseo, pero solo como objeto de arte para ser contemplado sin ser tocado y el perfume le permitirá dejar su huella invadiendo la consciencia del otro. También en su estela hay un mensaje, un código, una sutil rebeldía, unas ansias de libertad que quiere expresar al mundo. Corbin (1987) nos aproxima a esta idea de la autoexpresión contenida en la fragancia femenina:

La mujer quiere que se le aspire; afirma así su voluntad de autoexpresión. A través de esta alusión discreta a los ímpetus del cuerpo, mediante esa búsqueda del reflejo crea un aura de ensueño y deseo. La transferencia se bosqueja del mosaico olfativo a la frase olfativa. (p.87)

La protagonista de Ifigenia no solo se conforma con ser aspirada por el otro, sino que necesita también aspirarse a sí misma, por eso se perfuma en la intimidad de su habitación.

En la novela es determinante el estado etéreo, inmaterial, sublime y confiado que acompaña a María Eugenia cuando se dirige a conocer al pretendiente. Ella va irradiando seguridad y al llegar a la sala se enfrenta a otra fragancia con un mensaje muy diferente: el perfume de Leal (L'Origan de Coty) irrumpe en su estado y la hace bajar bruscamente de su pedestal de ensueño modificando su estado de consciencia, pasando a sentirse "de vencedora a vencida", debilitando sus intenciones, generando aversión hacia el pretendiente.

\section{L'Origan de Coty: aterrizaje forzoso}

El perfume de Leal, Origan de Coty, es determinante en el desenlace de la novela y el curso de los acontecimientos. La llegada del pretendiente a la vida de María Eugenia ocurre de forma drástica. Su presencia es intimidante para ella. Es un hombre que se hace notar, no pasa inadvertido, lo cual se refuerza con su perfume. Esto se puede percibir en la forma como lo describe María Eugenia en esta cita: "Imponente e imperial, de smoking con botonadura de rubíes en la pechera, una gardenia en el ojal, perfumado y con bellísimo solitario en el meñique de su mano derecha, se hallaba César Leal" (De la Parra, 1996, II, p.88).

Como podemos constatar en la cita anterior que muestra la descripción que hace María Eugenia de Leal, se resalta un despliegue de formalidad, indumentaria y perfume, realzado con la gardenia en el ojal. Si bien sabemos que María Eugenia es olfativa, esto nos constata que no solo los olores de la casa y del espacio privado captan su atención, también el olor de quienes la rodean. Ella es muy detallista, hace una toma de consciencia del otro a través de la apariencia exterior y los olores que emana. Como ya se ha dicho antes se puede ver que el perfume y los olores en la novela también se muestran como espejo que reflejan o retratan a determinados personajes: Abuelita se asocia con el olor del Elliman's Embrocation, que son las fricciones que usa para los dolores reumáticos; tía Clara es asociada al olor de las velas (cirio), el olor de Gabriel es a limpio, el de tío Pancho a brandy, el de Mercedes a embrujo y a flores, el de Leal a L'Origan de Coty y tabaco; y el de ella misma a Nirvana de Bichara. También el alma de la casa emana unos olores: los naranjos del patio, los azahares, la tierra húmeda. María Eugenia identifica cada personaje por su fragancia, así como a los espacios por el olor que se respira.

El olor de Leal invade los espacios y es como un golpe para la seguridad de María Eugenia. Desde que se produce el primer encuentro entre Leal y María Eugenia ella 
se siente vencida, aspirar el aroma de su perfume y todo el contexto de formalidad que le rodea le hacen perder la voluntad; se siente arrollada, atropellada, indefensa, vencida. La primera imagen que usa para definir a Leal es que se asemeja a un "árbol con raíces, ramas y todo", eso es lo que la apabulla, es un hombre terrenal, bien plantado en la tierra y viene a representar todo lo material, la seguridad económica, las posesiones, el poder. El brillante en el dedo meñique también hace el efecto de encandilarla, disolverla.

El Origan de Coty parece ser una fragancia que hace aterrizar-como su portador-. Su olor es penetrante, fuerte. Vale resaltar el efecto de los olores fuertes para el subconsciente: "Los olores fuertes agotan el psiquismo, engendran o avivan la inquietud, provocan a veces el estupor." (Corbin, 1987, p. 81). Se deduce entonces que María Eugenia es irrumpida e invadida por la fuerza del Origan de Coty y su intensidad.

En la muchacha se produce ese estupor apenas aspira el olor de Leal. Ella se encuentra elevada, sublimada, etérea, suave, con los olores de las flores de mayo que lleva en la cintura y el perfume Nirvana que la respalda, un estado parecido al "Nirvana" que alude el perfume; pero el olor de Leal la vence, le roba la voluntad como si de un elixir mágico se tratara. Todo el conjunto de olores que emana Leal la hacen aterrizar forzosamente, la despersonalizan, la disuelven, haciendo tambalear poco a poco su identidad.

Corbin considera que la relación entre el olfato y el cerebro se debe a su cercanía, por lo cual su efecto es muy rápido. Respecto a esa cercanía de la nariz y el cerebro nos explica: "Esa vecindad hace también que el olor pueda, según los casos, alegrar o ensombrecer el ánimo" (Corbin, 1987, p.75). Asimismo, afirma que "el comportamiento olfativo traduce e impone al conjunto del organismo a las disposiciones más secretas del individuo."
Vroon también nos explica la relación entre los olores y las emociones:

En general el significado de un olor se conecta con la información proporcionada por otros sistemas sensoriales. A diferencia de los demás sentidos, la interpretación última de las impresiones olfativas tiene lugar e influye sobre todo en aquellas zonas del cerebro que rigen las emociones, los sentimientos y la motivación (como son los núcleos amigdaloides del sistema límbico, el hipotálamo y el hemisferio derecho). Esto explica que las sensaciones olfativas provoquen a menudo una respuesta bastante directa que se traduce en una determinada conducta. Aún no se sabe con exactitud cómo funcionan estos procesos, pero no cabe la menor duda de que tienen lugar. (Vroon, 1999, p.161)

Como se ha mostrado, el perfume es un dispositivo que puede generar cambios en la percepción del entorno.

El efecto embriagador y determinante del perfume en las emociones puede resumirse en esta cita de Süskind (1982):

Porque los hombres podían cerrar los ojos ante la grandeza, ante el horror, ante la belleza y cerrar los oídos a las melodías o las palabras seductoras, pero no podían sustraerse al perfume. Porque el perfume era hermano del aliento. Con él se introducía en los hombres y si éstos querían vivir, tenían que respirarlo. Y una vez en su interior, el perfume iba directamente al corazón y allí decidía de modo categórico entre inclinación y desprecio, aversión y atracción, amor y odio. Quien dominaba los olores, dominaba el corazón de los hombres (p.148).

Como se ha venido explicando, el perfume es una tendencia estética que genera grandes movimientos de alma. Esos movimientos generados por los olores se ponen de manifiesto en Ifigenia, lo cual influye de forma trascendental en el desenlace de la novela. Esos movi- 
mientos de alma pueden apreciarse en el acercamiento a los aromas que están presentes en la obra, en concordancia con otros elementos, puesto que María Eugenia se fundamenta en esta fórmula para crear su imagen o identidad (espejo, indumentaria, maquillaje, peinado y perfume).

Aunque la protagonista no puede desafiar abiertamente al orden impuesto por la sociedad y la familia, el atuendo y el perfume se convierten en herramientas de poder que le permiten expresarse y crear una identidad buscando darse un cuerpo distinto al que la familia y el entorno pretenden darle. A través del cuerpo perfumado ella puede expresarse y recuperar su voz. Con el perfume y la indumentaria, el sujeto femenino juega a crearse un espacio en la sociedad y a través de estas herramientas expresa su mensaje, lo que no le está permitido decir con palabras, pero que el cuerpo emite a través de la frase olfativa.

\section{Referencias}

Balakian, A. (1969). El movimiento simbolista. Madrid: Ediciones Guadarrama, S.A.

Corbin, A. (1987). El perfume o el miasma: el olfato y el imaginario social. Siglos XVIII y XIX. México: Fondo de Cultura Económica.

Davis, M. (2006) Classic chic. Music, fashion, and modernism. Berkeley.

De la Parra, T. (1996). Ifigenia (Tomo I y II). Caracas: Monte Ávila Editores.

Freud, S. (2002). El malestar en la cultura. Madrid: Alianza Editorial.

Martínez, M. A. (1980). "Proust y Teresa de la Parra". En Velia Bosch. (Ed.) Teresa de la Parra ante la crítica (pp.145-154). Caracas: Monte Ávila Editores.

Mattalía, S. (1995). Idioma y Literatura: Flexiones de identidad. Estudios. Revista de investigaciones literarias y culturales, 3(6), (julio-diciembre), pp. 89-103.

Pisani, X. (2002). "Ifigenia de Teresa de la Parra o la nación entre cuatro paredes". Ponencia XXVIII Simposio de Docentes e Investigadores de la Literatura Venezolana. Sartenejas, Universidad Simón Bolívar, (pp.1-9).

Sáez, B. (2007). "Formas de identidad contemporánea". En Meri Torras (ed.) Cuerpo e identidad I (pp. 41-53). Barcelona: Ediciones UAB.

Süskind, P. (1986) El perfume. Historia de un asesino. Barcelona: Editorial Seix Barral.

Squicciarino, N. (1990). El vestido habla: consideraciones psico-sociológicas sobre la indumentaria. Madrid: Editorial Cátedra.

Torras, M. (2007). "El delito del cuerpo. De la evidencia del cuerpo al cuerpo en evidencia". En Meri Torras (Ed.) Cuerpo e identidad I (pp. 11-36). Barcelona: Ediciones UAB.

Vroon, P. (1999) La seducción secreta. Psicología del olfato. Barcelona: Tusquets Editores.

Weil, A. (2000). La moda parisina: La Gazette du bon ton 1912-1925. París. Bibliothèque de I'Image. 